\title{
Changes in thyroid hormones, thyroid stimulating hormone and cortisol in acute spinal cord injury
}

\author{
J M Bugaresti MD FRCPC,${ }^{1} \mathrm{C}$ H Tator MD PhD FRCSC, ${ }^{1 *} \mathrm{~J}$ D Silverberg MD \\ FRCPC FACP,${ }^{2} \mathrm{~J}$ P Szalai PhD,${ }^{3} \mathrm{D}$ G Malkin MD MSc ${ }^{4}$ A Malkin MD FRCPC, ${ }^{4} \mathrm{~S} \mathrm{~K}$
} Tay $\mathrm{MSc}^{4}$

Spinal Cord Injury Treatment, Research, and Prevention Centre, Toronto Western Hospital, University of Toronto; ${ }^{2}$ Department of Endocrinology, ${ }^{3}$ Department of Statistics ${ }^{3},{ }^{4}$ Department of Clinical Biochemistry, Sunnybrook Medical Centre, University of Toronto, Toronto, Ontario, Canada.

To determine the hormonal response to acute spinal cord injury, serial serum samples were collected from 18 patients with acute spinal cord injury and from 14 control patients with spinal fractures without cord injury. The first sample was taken within 24 hours of injury, the second at 24-48 hours; and the third at 7 days for determination of thyroxine (T4), free T4 (FT4), triiodothyronine (T3), reverse T3 (rT3), T3 uptake (T3U), thyroid stimulating hormone (TSH), thyroxine binding globulin (TBG), growth hormone $(\mathrm{GH})$, cortisol, and insulin. Significant increases were observed in rT3 levels and transient changes were observed in the T4 and T3 levels in the spinal cord injured group but not in the group with spinal fractures alone. The changes in the spinal cord injured patients are consistent with the 'low T3 syndrome'. However, the persisting rise of rT3 at 7 days was an unexpected finding. In addition to the cord injury, these changes may also be related to dexamthasone administration and nutritional factors.

Key words: thyroid hormones; cortisol; acute spinal cord injury; metabolic response to injury.

\section{Introduction}

The importance of thyroid hormone function for the normal development of the nervous system is well recognized. ${ }^{1}$ However, the role of thyroid hormones in repair and regeneration of the injured, adult nervous system remains uncertain. In the laboratory, the administration of exogenous thyroid hormones has been associated with improved functional recovery following trauma to the peripheral and central nervous systems. ${ }^{2}$ For example, after acute spinal cord injury in animal models, T4, T3, thyrotrophin releasing hormone (TRH) and TRH analogs have each been associated with improved functional recovery. Harvey and Srebnik $^{3}$ demonstrated improved re-

\footnotetext{
*Correspondence: Room 2002, Edith Cavell Wing. Toronto Western Hospital, 399 Bathurst Street, Toronto, Ontario, Canada, M5T 2S8.
}

generation of axons after crush injuries of the spinal cord in the rat. Tator et $a l^{4}$ demonstrated slightly improved functional recovery in spinal cord injured rats when exogenous T3 was administered for 2 weeks following spinal cord injury, although this result was not reproduced in a subsequent study with similar doses of T3. ${ }^{5}$ In these studies, the enhanced functional recovery was thought to be related to axonal regeneration due to the effect of thyroid hormones on the neurons themselves. Faden $e t a l^{6}$ reported improved functional recovery in cats following administration of TRH within 24 hours of acute spinal cord injury. It is not known how TRH improves outcome after spinal cord trauma, but its action may be through alteration of the effects of vasoactive factors important in a secondary mechanism of injury such as ischemia, ${ }^{7.8}$ rather than by stimulating regeneration. 
After acute spinal cord injury in the rat, it has been shown that both T4 and TSH were depressed at one minute following injury. ${ }^{4}$ The depression in T4 persisted for 3 days but the levels of TSH showed significant recovery within 24 hours. When these results were compared with those of a control group of rats subjected to laminectomy without cord injury, the depression in T4 was found to be greater in the spinal cord injury group than in the laminectomy group alone. The greater depression of $\mathrm{T} 4$ in the cord injured group was thought to be a consequence of the increased stress. It is not known whether correction of this postinjury depression of thyroid hormone might enhance recovery.

In man, Claus Walker et $a l^{9}$ found low circulating levels of T3 and T4 2 to 6 months following spinal cord injury. However, a later study by these authors confirmed the low circulating T4 levels but failed to confirm low T3 levels. ${ }^{10}$ Prakash et al ${ }^{11}$ demonstrated that low normal or subnormal levels of T3 persisted for up to 3 months following spinal cord injury, with more marked changes seen in quadriplegic than in paraplegic patients. Because of the reported benefits of exogenous thyroid hormone and TRH administration in the animal models and the reported depressed levels in man, further study of thyroid hormone levels in man in the initial week following injury was considered to be of value. The present study reports circulating thyroid hormone levels in patients in the first week after acute spinal cord injury as compared with a control group of patients with spinal fractures without cord injury.

\section{Materials and methods}

\section{Patients}

The cord injury group consisted of 18 patients with acute spinal cord injury and the control group consisted of 14 patients with spinal fractures without cord injury, all of whom were admitted to the Acute Spinal Cord Injury Unit at Sunnybrook Medical Centre between July 1983 and July 1984 (Table I). Patients with a history of thyroid dysfunction, exogenous thyroid administration or thyroid nodules, and patients receiving $125 \mathrm{I}$-fibrinogen screening for detection of deep venous thrombosis were excluded from the study. In each group all but one of the subjects were male. In the spinal cord injury group 15 of the 18 patients had cervical injuries. The severity of neurological deficit graded according to the Spinal Cord Injury Scale ${ }^{24}$ and the overall severity of trauma graded according to the Injury Severity Score ${ }^{12}$ were documented (Table I). The mean time from injury to the initial venopuncture for collection of a blood sample and the number of patients receiving dexamthasone were noted. In addition the nutritional support, transfusions, and medications were recorded. All patients with spinal cord injury and 12 of the 14 patients in the control group received calories intravenously during the initial 24

Table I Age, neurological deficit, injury severity score, and time from injury to initial venopuncture in each patient group

\begin{tabular}{lcccccc}
\hline Group & $\begin{array}{c}\text { No. of } \\
\text { Patients }\end{array}$ & $\begin{array}{c}\text { Age (years) } \\
\text { mean } \pm \text { SD }\end{array}$ & $\begin{array}{c}\text { SCIS* }_{\text {Mean }}^{*} \\
\text { SD }\end{array}$ & $\begin{array}{c}\text { ISS } \\
\pm \text { Mean } \\
\text { SD }\end{array}$ & $\begin{array}{c}\text { Time from injury } \\
\text { to initial } \\
\text { venopuncture } \\
\text { (hours) mean } \pm \\
\text { SD }\end{array}$ & $\begin{array}{c}\text { No. of patients } \\
\text { receiving steroids }\end{array}$ \\
\hline $\begin{array}{l}\text { Spinal cord } \\
\text { injury }\end{array}$ & 18 & $29 \pm 8$ & $1.8 \pm 1.6$ & $26 \pm 13$ & $9.9 \pm 7.4$ & 13 \\
Spinal fracture & 14 & $29 \pm 13$ & $10 \pm 0$ & $12 \pm 7$ & $9.0 \pm 6.9$ & 1 \\
\hline
\end{tabular}

${ }^{*}$ SCIS $=$ Spinal Cord Injury Scale, according to Tator et al ${ }^{24}$ where $1=$ a complete spinal cord injury and $10=$ no neurological deficit.

${ }^{\mathrm{t}} \mathrm{ISS}=$ Injury severity score according to Baker et al. ${ }^{12}$ 
hours following hospital admission. Intravenous calories remained the sole nutrient source for 5 of the 18 spinal cord injured patients and for 2 of 14 control patients during the second day following injury. At 7 days after injury, all patients were receiving either a regular diet or a full strength dietary supplement. Three patients with spinal cord injury and 3 control patients received transfusions during the study period. Three of the 6 were excluded from data analysis because of massive blood or plasma transfusions or transfusions of plasma during the study period. The 3 remaining patients, each of whom received 2 units of packed cells were included in the data analysis. Several medications known to affect levels of circulating thyroid hormones were used. For example, 13 of 18 patients in the spinal cord injury group, and one of 14 in the control group received dexamthasone. Dopamine, known to lower TSH levels, ${ }^{13}$ was administered to one patient in the spinal cord injury group, and 3 patients ( 2 with spinal cord injury and one without) received subcutaneous heparin. No patients received propranolol or diphenylhydantoin.

\section{Blood samples}

Serial blood samples were collected in the following manner: the intial blood sample was collected during the first 24 hours following injury; the second sample was collected 24-28 hours after the first sample; and the final sample was a fasting sample collected 7 days following injury. In the spinal cord injured group all 3 samples were obtained from 10 of 18 patients and 2 samples from the remaining 8 patients. Early discharge from hospital prevented collection of the third sample in 9 of the 14 control subjects. All 3 samples were collected from the remaining 5 patients in the control group.

\section{Assays}

Serum samples were analyzed for the following: T4, FT4, T3U, T3, rT3, TBG, TSH, thyroid antibodies, cortisol, growth hormone and insulin. The following techniques were used:
1 T4: T4 BIO-RIA, Radioimmunoassay (normal range 60-155 nmol/1).

2 Free T4: Corning Free T4 [125] Radioimmunoassay (normal range 12$32 \mathrm{pmol} / 1)$.

3 T3U: Beckman RIAphase T3Uptake (normal range $0.25-0.35$ ). A change to Tri-Tab T3Uptake, Nuclear Medical Laboratory (NML) occurred late in the study period (new normal range $0.35-0.45)$. Determinations of T3U affected by the new normal range are indicated in the text by an asterisk.

4 T3: T3 RIABEAD ${ }^{\mathrm{TM}}$, Abbott Laboratories (normal range $1.2-3.4 \mathrm{nmol} / \mathrm{l}$ ).

5 rT3: Reverse T3 RIAKIT, Serno Laboratories (normal range $0.12-0.54 \mathrm{nmol} / \mathrm{l}$ ).

6 TBG: Corning IMMOPHASE TBG [125] Radioimmunoassay (normal range $15-30 \mathrm{mgm} / \mathrm{l}$ ).

7 TSH: Beckman RIAphase HTSH (normal range 2-10 IU/1).

\section{Data analysis}

A 3 by 2 factorial design with patient group ( 2 levels) and serum rT3 levels over time ( 3 levels) was analyzed using repeated measures analysis of variance. Because of a lack of a third sample in many patients in the control group, the remainder of the analyses of thyroid hormones were based on a 2 by 2 factorial design using only the hormone levels at $0-24$ and 24-48 hours following injury to ensure adequate power for the multiple tests required. The TSH, growth hormone, cortisol and insulin levels were also analyzed by the 2 by 2 factorial design. The subjects were then pooled, regrouped for the presence of multiple trauma, and the severity of neurological deficit or the use of dexamethasone, and then subjected to repeated measures analysis of variance to determine the effects of these factors on the changes in rT3 observed over time.

\section{Results}

Serum T4 and T3 were significantly decreased within 48 hours of injury in patients with spinal cord injury but not in patients 
with spinal fractures alone (Fig 1(a) and (b)). Free $\mathrm{T} 4$ also decreased and $\mathrm{TSH}$ increased in both patients groups within the initial 24 hours but the changes observed

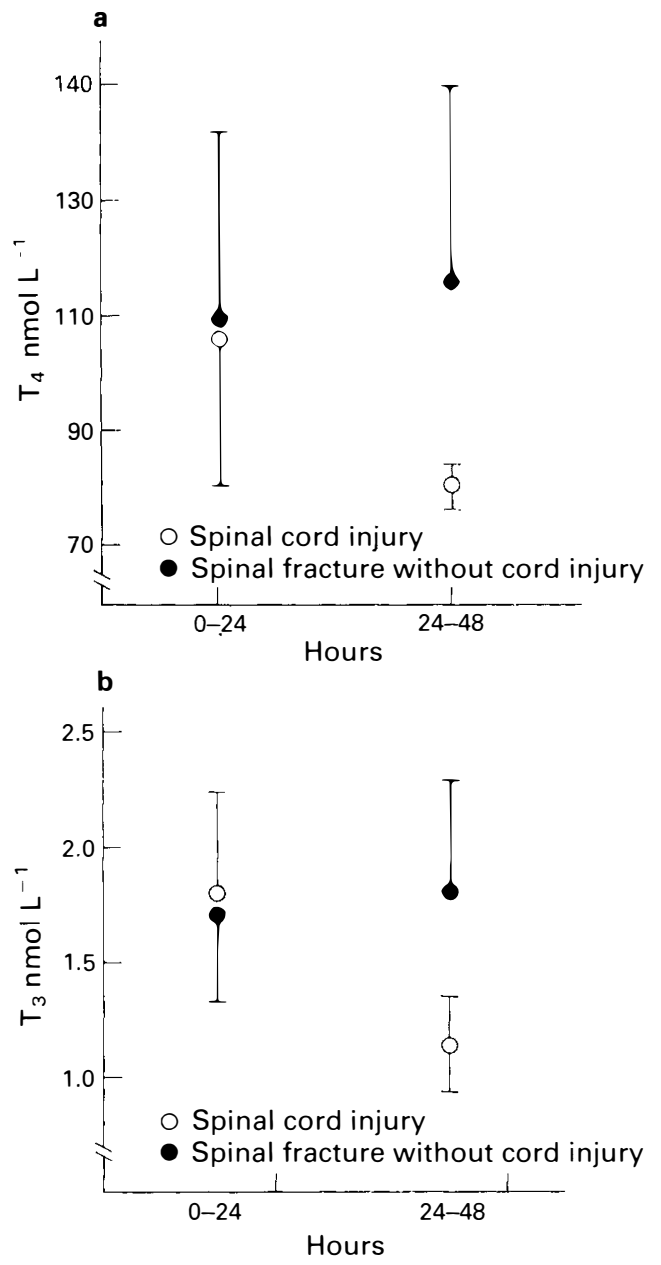

Figure 1 (a) Serum thyroxine levels (mean \pm SEM) 0-24 hours and 24-48 hours after injury in 12 patients with spinal cord injury and in 13 patients with spinal fractures alone. Normal range for serum thyroxine is $60-155 \mathrm{nmol} / \mathrm{l}$. A significant interaction between group and $\mathrm{T}_{4}$ over time is demonstrated using repeated measures analysis of variance, $p<.001$. (b) Serum triiodothyronine levels (mean \pm SEM) 0-24 and 24-48 hours after injury for 13 patients with spinal cord injury and 11 patients with spinal fractures alone. Normal range of triiodothyronine is $1.2-3.4 \mathrm{nmol} / \mathrm{l}$. A significant interaction is present between group and $T_{3}$ levels over time, $p<.0001$. were not significant $(p>.05)$ (Table II). Each of these hormones returned to baseline levels by the seventh day following injury.

A significant interaction between group and time was found for mean rT3 levels (Fig 2). The rise in rT3 in the spinal cord injured group continued to the seventh day following injury.

Significant interactions between group and time were not demonstrated for T3U, $\mathrm{TSH}, \mathrm{TBG}$, insulin or growth hormone. Insulin levels determined within 24 hours of injury and fasting levels at 7 days following injury were within normal limits in both patient groups. Growth hormone levels within 24 hours of injury were initially above the normal range in one-third of patients with spinal cord injuries and with spinal fractures alone, but subsequent measurements in these patients were within the normal range. Several patients with normal growth hormone levels in the first 24 hours later showed elevations above the normal range. There was no significant relationship between the changes in growth hormone and level, type of injury, or changes in circulating thyroid hormone levels or serum cortisol levels.

Eleven of 18 patients with acute spinal cord injury and 4 of 14 patients in the control group had serum cortisol levels above the normal range at 0-24 hours after injury, but mean serum cortisol levels in both groups were within the normal range. At 24-48 hours and 7 days following injury cortisol levels decreased significantly only in patients with spinal cord injury who received glucocorticoids. The serum cortisol levels in the spinal cord injury group who did not receive dexamethasone were similar to the levels in the control group with spinal fractures without cord injury (Table III).

Five patients with complete cervical injuries who did not receive dexamethasone were compared with 9 patients with spinal cord injury who received loading doses of 4-10 mgm of dexamethsaone intravenously followed by $4 \mathrm{mgm}$ of dexamethasone every 6 hours. These patients received tapering doses of dexamethasone which were usually discontinued by the seventh day following injury. The reductions in T3, T4 and FT4 at 
Table II Circulating thyroid hormones, TSH and TBG levels (mean \pm SEM) for patients with cord injuries and patients with spinal fractures alone

\begin{tabular}{|c|c|c|c|c|c|c|}
\hline \multirow[b]{2}{*}{ Hormones } & \multicolumn{2}{|c|}{$0-24$ hours } & \multicolumn{2}{|c|}{$\begin{array}{l}\text { Sampling time } \\
24-48 \text { hours }\end{array}$} & \multicolumn{2}{|c|}{7 days } \\
\hline & Cord injury & Spinal fracture & Cord injury & Spinal fracture & Cord injury & $\begin{array}{c}\text { Spinal } \\
\text { fracture }\end{array}$ \\
\hline $\mathrm{rT}_{3} *$ & $.36 \pm .16$ & $.45 \pm .13$ & $.54 \pm .18$ & $.52 \pm .14$ & $.66 \pm .20$ & $.52 \pm .13$ \\
\hline $\mathrm{T}_{4} * * *$ & $106.1 \pm 7.6$ & $108.9 \pm 9.2$ & $85.42 \pm .42$ & $116.7 \pm 9.7$ & $123.0 \pm 8.9$ & $148.3 \pm 8.3$ \\
\hline $\mathrm{FT}_{4}^{* *}$ & $21.08 \pm 1.0$ & $22.47 \pm 1.4$ & $17.88 \pm .51$ & $21.49 \pm 1.2$ & & \\
\hline $\mathrm{T}_{3} \mathrm{U}$ & $.32 \pm .13$ & $.37 \pm .21$ & $.32 \pm .13$ & $.37 \pm .22$ & $.34 \pm .24$ & $.32 \pm .10$ \\
\hline $\mathrm{T}_{3} \mathrm{RIA}^{* * * *}$ & $1.82 \pm .15$ & $1.83 \pm .13$ & $1.14 \pm .60$ & $1.73 \pm .11$ & $1.39 \pm .14$ & $1.65+.16$ \\
\hline TSH & $3.54 \pm .64$ & $4.94 \pm .66$ & $4.00 \pm .73$ & $5.61 \pm .48$ & $5.3 \pm .53$ & $4.2 \pm .67$ \\
\hline TBG & $19.12 \pm 1.1$ & $19.21 \pm .96$ & $18.06 \pm .17$ & $19.39 \pm 1.8$ & $18.3 \pm .97$ & $25.2 \pm 3$ \\
\hline
\end{tabular}

Using repeated measures analysis of variance, significant interactions were detected between patient group (spinal cord injury and spinal fracture alone groups) and changes in thyroid hormone levels over time as indicated: ${ }^{*} p<.02,{ }^{* *} p<.01,{ }^{* * *} p<.008,{ }^{* * * *} p<.0001$.

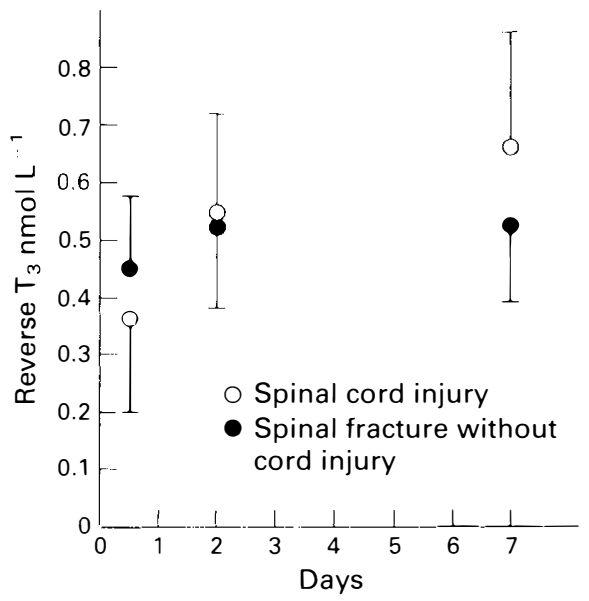

Figure 2 Reverse $\mathrm{T}_{3}$ levels (mean $\pm \mathrm{SEM}$ ) in 12 patients with spinal cord injury and in 14 patients with spinal fracture alone. Normal range for $\mathrm{rT}_{3}$ is .16-.54 nmol/l. An interaction is present between the 2 patient groups and $\mathrm{rT}_{3}$ levels over time, $p<.02$.

48 hours were less evident in the group of patients who did not receive glucocorticoids (Table IV). Reverse T3 rose in all 5 patients who did not receive dexamethasone although in 2 the rise was less marked. TSH levels increased but in each case the level remained within the normal range. Changes in T3U and TBG over time were similar for patients who received dexamethasone and those who did not.
Patients with spinal cord injury and those with spinal fractures alone grouped on the basis of the injury severity score showed no significant interaction between group and time for mean rT3 levels. However, when patients were regrouped on the basis of neurological deficit and compared, a significant interaction between the severity of neurological deficit and time was demonstrated $(p<.003)$ (Fig 3$)$.

\section{Discussion}

It has been shown previously that circulating thyroid hormone levels in man are depressed for 2 to 6 months following spinal cord injury, ${ }^{9,11.14}$ although changes in the acute stage have not been reported. In the present study, significant reduction in $\mathrm{T} 4$ and T3 levels occurred within 48 hours of trauma in patients with acute cord injury, but the levels returned to baseline by 7 days following injury. The relationship of these findings to those of the earlier studies which demonstrated depressed thyroid hormone levels persisting for months after injury is uncertain.

Acute changes in circulating thyroid hormone levels have been examined in non spinal experimental trauma ${ }^{15}$ and in patients with severe abdominal trauma and multiple injuries excluding spinal trauma. ${ }^{16,17}$ Phillips et al found that decreases in $\mathrm{T} 3$ persisted for 
Table III Serum cortisol levels (mean \pm SEM nmol/l) in patients with spinal cord injuries and in patients with spinal fractures alone

\begin{tabular}{lcccc}
\hline Group & $\begin{array}{c}\text { No. of } \\
\text { patients }\end{array}$ & $0-24$ hrs & $\begin{array}{c}\text { Interval } \\
\text { from trauma } \\
24-48 \text { hrs }\end{array}$ & 7 days \\
\hline $\begin{array}{c}\text { Spinal fracture } \\
\text { without steroids }\end{array}$ & 13 & $479 \pm 132$ & $461 \pm 70$ & $309 \pm 33$ \\
$\begin{array}{c}\text { Spinal fracture } \\
\text { with steroids }\end{array}$ & 1 & 347 & 15 & - \\
$\begin{array}{c}\text { Spinal cord injury } \\
\text { without steroids }\end{array}$ & 5 & $636 \pm 168$ & $477 \pm 160$ & $413 \pm 63$ \\
$\begin{array}{c}\text { Spinal cord injury } \\
\text { with steroids }\end{array}$ & 13 & $652 \pm 70$ & $186 \pm 62$ & $40 \pm 9$ \\
\hline
\end{tabular}

Table IV $\mathrm{rT}_{3}, \mathrm{~T}_{4}, \mathrm{FT}_{4}, \mathrm{~T}_{3}, \mathrm{~T}_{3} \mathrm{U}, \mathrm{TBG}, \mathrm{TSH}$ and cortisol in spinal cord injured patients not receiving steroids

\begin{tabular}{|c|c|c|c|c|c|c|}
\hline $\begin{array}{l}\text { Hormones and } \\
\text { normal ranges }\end{array}$ & $\begin{array}{l}\text { Interval } \\
\text { from trauma }\end{array}$ & 5 & 6 & $\begin{array}{l}\text { Subject no. } \\
\quad 15\end{array}$ & 18 & 27 \\
\hline $\begin{array}{l}\mathrm{rT}_{3} \\
(.12-.54 \mathrm{nmol} / \mathrm{l})\end{array}$ & $\begin{array}{l}0-24 \\
24-48 \\
7 \text { days }\end{array}$ & $\begin{array}{l}.29 \\
.39 \\
.48\end{array}$ & $\begin{array}{l}.18 \\
.28 \\
.60\end{array}$ & $\begin{array}{l}.22 \\
.47 \\
-\end{array}$ & $\begin{array}{l}- \\
.43 \\
.52\end{array}$ & $\begin{array}{c}.37 \\
-.45\end{array}$ \\
\hline $\begin{array}{l}\mathrm{T}_{4} \\
(60-155 \mathrm{nmol} / \mathrm{l})\end{array}$ & $\begin{array}{l}0-24 \\
24-48 \\
7 \text { days }\end{array}$ & $\begin{array}{l}64 \\
54 \\
95\end{array}$ & $\begin{array}{l}65 \\
99 \\
96\end{array}$ & $\begin{array}{r}119 \\
78 \\
92\end{array}$ & $\begin{array}{r}71 \\
118\end{array}$ & $\begin{array}{r}73 \\
11 \overline{5}\end{array}$ \\
\hline $\begin{array}{l}\mathrm{FT}_{4} \\
(12-32 \mathrm{pmol} / \mathrm{l})\end{array}$ & $\begin{array}{l}0-24 \\
24-48 \\
7 \text { days }\end{array}$ & $\begin{array}{l}16.7 \\
14.3 \\
19.4\end{array}$ & $\begin{array}{l}18.7 \\
18.3 \\
21.1\end{array}$ & $\begin{array}{c}19.2 \\
16.3 \\
-\end{array}$ & $\begin{array}{r}- \\
15.8 \\
20.7\end{array}$ & $\begin{array}{c}15.0 \\
- \\
19.0\end{array}$ \\
\hline $\begin{array}{l}\mathrm{T}_{3} \\
(1.2-3.4 \mathrm{nmol} / \mathrm{l})\end{array}$ & $\begin{array}{l}0-24 \\
24-48 \\
7 \text { days }\end{array}$ & $\begin{array}{l}1.3 \\
1.0 \\
1.2\end{array}$ & $\begin{array}{l}1.4 \\
1.6 \\
2.1\end{array}$ & $\begin{array}{l}2.5 \\
1.1 \\
-\end{array}$ & $\begin{array}{l}-\overline{1.0} \\
1.5\end{array}$ & $\frac{1.2}{1.9}$ \\
\hline $\begin{array}{l}\mathrm{T}_{3} \mathrm{U} \\
(25-35) \\
*(35-45)\end{array}$ & $\begin{array}{l}0-24 \\
24-48 \\
7 \text { days }\end{array}$ & $\begin{array}{l}.39 \\
.39 \\
.53^{*}\end{array}$ & $\begin{array}{l}.36 \\
.31 \\
.30\end{array}$ & $\begin{array}{l}.38^{*} \\
.39^{*} \\
-\end{array}$ & $\begin{array}{l}.49^{*} \\
.41^{*}\end{array}$ & $\begin{array}{c}.32 \\
-.32\end{array}$ \\
\hline $\begin{array}{l}\text { TBG } \\
(15-30 \mathrm{mg} / \mathrm{l})\end{array}$ & $\begin{array}{l}0-24 \\
24-48 \\
7 \text { days }\end{array}$ & $\begin{array}{l}10.1 \\
10.3 \\
11.7\end{array}$ & $\begin{array}{l}18.3 \\
20.5 \\
22.2\end{array}$ & $\begin{array}{l}23.1 \\
21.9 \\
-\end{array}$ & $\begin{array}{r}\overline{15.4} \\
21.2\end{array}$ & $\begin{array}{c}16.3 \\
-- \\
20.3\end{array}$ \\
\hline $\begin{array}{l}\text { TSH } \\
(2-10 \mathrm{IU} / \mathrm{l})\end{array}$ & $\begin{array}{l}0-24 \\
24-48 \\
7 \text { days }\end{array}$ & $\begin{array}{l}3.2 \\
7.6 \\
7.6\end{array}$ & $\begin{array}{l}3.3 \\
3.7 \\
5.5\end{array}$ & $\begin{array}{r}9.5 \\
10.5 \\
-\end{array}$ & $\begin{array}{l}\overline{4.2} \\
5.8\end{array}$ & $\frac{3.5}{10.2}$ \\
\hline $\begin{array}{l}\text { Cortisol } \\
(160-660 \mathrm{nmol} / \mathrm{l})\end{array}$ & $\begin{array}{l}0-24 \\
24-48 \\
7 \text { days }\end{array}$ & $\begin{array}{l}974 \\
121 \\
444\end{array}$ & $\begin{array}{l}441 \\
972 \\
536\end{array}$ & $\begin{array}{r}774 \\
374 \\
-\end{array}$ & $\begin{array}{l}- \\
443 \\
463\end{array}$ & $\begin{array}{r}452 \\
210\end{array}$ \\
\hline
\end{tabular}

*Values affected by the new normal range (35-40) are indicated by an asterisk.

the duration of the 14-day study period, but the depression of $\mathrm{T} 4$ was only seen in patients with fatal injuries. Because of the finding of reduced $\mathrm{T} 4$ in only fatal injuries,
Phillips postulated that measures of $\mathrm{T} 4$ could be of prognostic value for patients with severe multiple system trauma. Reverse T3 levels in survivors of major trauma 


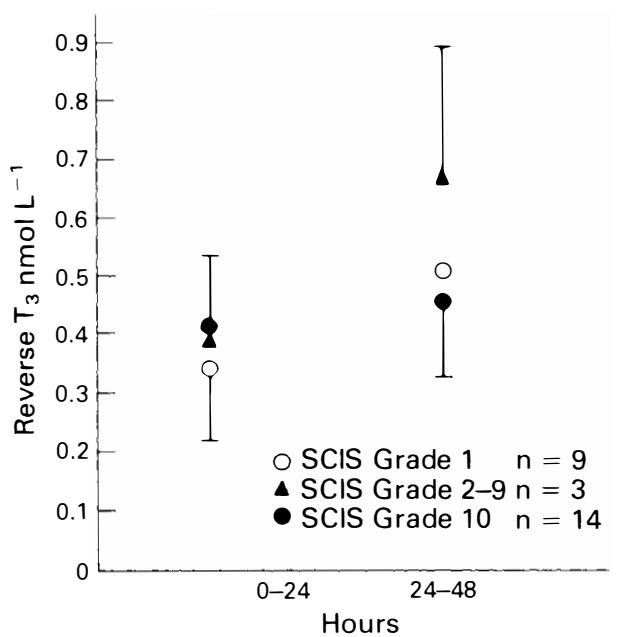

Figure 3 Reverse $T_{3}$ (mean \pm SEM) in 26 patients with varying degrees of neurological deficit. A significant interaction is present between groups with varying degrees of neurological deficit and $\mathrm{rT}_{3}$ levels over time $(p<.0003)$.

were maximally increased 12 hours following injury and then decreased over the following weeks. In experimental trauma, the rise in rT3 was also transient. ${ }^{15}$ Thus, in the cord injured patients in the present study the depression in $\mathrm{T} 3$ and $\mathrm{T} 4$ at 48 hours, the subsequent recovery of these levels within 7 days, and the persistent rise in rT3, contrast with the findings in patients with other types of major trauma.

Many factors are known to affect levels of circulating thyroid hormones including activity level, nutritional status, trauma, drugs, age, and systemic illness. In healthy man confined to bedrest, the normal circadian variation in T3 and T4 disappears, and T3 levels gradually rise, although T4 levels remain constant. ${ }^{18}$ Low $\mathrm{T} 3$ and low $\mathrm{TSH}$ levels have been found in fasting patients ${ }^{13}$ but as little as 50 grams of carbohydrate was sufficient to reverse fasting induced alterations in thyroid hormones towards normal. ${ }^{19}$ There is controversy about the differential effects on hormone levels between the intravenous versus the oral route for the administration of calories..$^{20.21}$ Changes in T3 and T4 levels in pigs subjected to trauma depended upon the type of injury sustained: ${ }^{15}$ abdominal injury caused the most marked changes, followed by missile trauma to the hind leg and preparative surgery only. Glucocorticoids, but not mineralocorticoids cause depression of T3, T4 and TSH and elevation of $\mathrm{rT} 3 .^{21}$ In healthy volunteers, a dose-response relationship was found for both T3 and T4 with increasing oral doses of betamethasone, up to $4.5 \mathrm{mg}$. ${ }^{22}$

Wartofsky and Burman ${ }^{13}$ have designated conditions with similar changes in thyroid hormones to those of the 'euthyroid sick' or 'low T3 syndrome' which is characterized by normal to low T3, elevated rT3 and a normal or low serum T4. Basal TSH levels are normal but the TRH response is blunted. These changes are thought to be dependent upon alterations in the activity of the enzyme $5^{\prime}$ deiodinase which is responsible for both the conversion of $\mathrm{T} 4$ to $\mathrm{T} 3$ and for the conversion of rT3 to its metabolites. Changes in the concentration of $\mathrm{T} 4$ are thought to be related to changes in protein binding. The presence of this syndrome does not indicate a hypothyroid state, but it may confuse the diagnosis of hypothyroidism in affected patients. It has been suggested that the decrease in $\mathrm{T} 3$ and $\mathrm{T} 4$ and increase in the metabolically inactive rT3 may provide individuals with a protective adaptive response to stress, ${ }^{16}$ through which protein catabolism is reduced beginning 24-48 hours after injury and persisting for 7 days or longer. The findings in the present study are consistent with the low T3 syndrome in patients with acute spinal cord injuries at 24-48 hours after trauma.

Previous studies of the neuroendocrine changes after spinal cord injury have suggested that function of the hypothalamicpituitary-adrenocortical (HPAC) axis is altered. Although normal resting serum cortisol levels and normal responses to ACTH have been reported in spinal cord injured patients one to 6 months following injury, ${ }^{9.23}$ patients with paraplegia and quadriplegia did not demonstrate the expected rise in serum cortisol in response to hypotension due to passive tilt. ${ }^{9}$ In addition, surgical procedures below the level of injury in these patients did not elicit a rise in urinary 17 hydroxycorticosteroids (17- 
OHCS) in the 3 days following surgery. The lack of adrenocortical response was thought to be due to interruption of afferent pathways to the hypothalamus. In contrast, systemic signals such as those accompanying infection caused an elevation of 17-OHCS, and a delayed response occurred after a cold stimulus to the lower extremities. ${ }^{14}$ Thus it appears that systemic stimuli, including blood-borne substances, can activate the hypothalamus and cause increased ACTH output, though this response may be delayed. Because serum cortisol levels at $0-24$ hours after injury in the present study were similar for patients with and without cord injury, evidence to support the concept of delayed glucocorticoid output as a result of acute cord injury was not obtained. Thus, it appears that systemic factors successfully elicited an appropriate hypothalamic response in the spinal cord injured patients. The influence of alterations in the hypothalamic-pituitary axis on the levels of circulating thyroid hormones in acute spinal cord injury remains to be determined.

In the present study, patients with spinal cord injuries were compared to patients with spinal fractures without cord injuries in an attempt to control such factors as the stress of trauma, immobilization, and limited oral intake during the initial 48 hours following injury. Thus, the major difference between the 2 groups was the presence of the severe neurological deficit in the cord injured group and the use of dexamethasone in 13 of the 18 patients in this group. The effect of dexamethasone on the results of this study remains uncertain. With the limited sample size in this study, it was not possible to determine the effects of dexamethasone and neurological deficit independently. However, we do not feel that decadron was entirely responsible for the observations regarding $\mathrm{T} 3$, T4 and $\mathrm{rT} 3$, as similar trends in the data were noted for patients who did not receive this medication (Table IV). Analysis of larger numbers of patients re- ceiving and not receiving decadron would be required to clarify the contribution of this medication to the changes noted after acute spinal cord injury.

The significance of the low T3 syndrome after spinal cord injury also remains uncertain. Aun et $a l^{16}$ have postulated that the decrease in $\mathrm{T} 3$ and $\mathrm{T} 4$ may provide a protective or adaptive response to stress. In experimental spinal cord injury low T4 levels were also found after cord injury, and it was shown that exogenous hormones enhanced functional recovery. ${ }^{4}$ At this point, we do not recommend the use of exogenous thyroid hormones following acute spinal cord injury in man, although we recognize that the low $\mathrm{T} 3$ syndrome in this condition may not constitute the optimal homeostatic condition for recovery or regeneration of the nervous system.

In summary, changes in circulating thyroid hormones in the initial week following spinal cord injury are consistent with the changes seen in the 'low T3 syndrome'. However, the persisting elevation of rT3 is not consistent with the changes in rT3 reported in other patient groups with trauma. Elevated serum cortisol levels in the initial week following injury support previous research suggesting that the hypothalamic-pituitary-adrenal axis remains responsive to systemic factors after acute spinal cord injury. Study of a larger population of spinal cord injured patients not receiving glucocorticoids is required to determine the relative contribution of the neurological injury to changes in circulating thyroid hormones and TSH.

Further study of the relationships between the severity of trauma, the glucocorticoid response, and the changes in circulating thyroid hormones is required to determine whether the changes observed in this study are a protective mechanism or whether they may be harmful to the neurological status and survival of patients with acute spinal cord injury.

\section{References}

1 Keirnan JA (1979) Hypotheses concerned with regeneration of the mammalian nervous system. Biol Rev 54: $155-197$. 
2 Cook RA and Keirnan JA (1976) Effects of triiodothyronine on protein synthesis in regenerating peripheral neurons. Exp Neurol 52: 515-524.

3 Harvey JE and Srebnik HH (1967) Locomotor activity and axon regeneration following spinal cord compression in rats treated with L-thyroxine. J Neuropathol Exp Neurol 26: 661-668.

4 Tator CH, van der Jagt RHC (1980) The effect of exogenous thyroid hormones on functional recovery of the rat after acute spinal cord compression injury. J Neurosurg 53: 381-384.

5 Tator CH, Rivlin AS, Lewis AJ and Schmoll B (1983) Effect of triiodo-L-thronine on axonal regeneration in the rat spinal cord after acute compression injury. J Neurosurg 58: 406-409.

6 Faden AI, Jacobs TP and Smith TM (1984) Thyrotropin-releasing hormone in experimental cord injury: dose response and late treatment. Neurology (Cleveland) 34: 1280-1284.

7 Faden AI and Jacob TP (1985) Effect of TRH analogs on neurologic recovery after experimental spinal trauma. Neurology 35: 1331-1334.

8 Faden AI, Vink R and McIntosh TK (1989) Thyrotropin-releasing hormone and central nervous system trauma. Ann NY Acad Sci 553: 380-384.

9 Claus-Walker J, Vallbona C, Carter RE, Lipscomb HS (1971) Resting and stimulated endocrine function in human subjects with cervical cord transection. J Chron Dis 24: 193-207.

10 Claus-Walker J, Halstead LS, Carter RE, Campos RJ, Spencer WA (1976) Biochemical responses to intense local cooling in healthy subjects and in subjects with cervical spinal cord injury. Arch Phys Med Rehabil 57: 50-54.

11 Prakash V, Lin MS, Song CH, Perkash I (1980) Thyroid hypofunction in spinal cord injury patients. Paraplegia 18: 56-53.

12 Baker S, O'Neill B, Hadden W and Long WB (1974) The Injury Severity Score: a method for describing patients with multiple injuries and evaluating emergency care. J Trauma 14: 187-191.

13 Wartofsky L and Burman KD (1982) Alterations in thyroid function in patients with systemic illness: 'The Euthyroid Sick Syndrome'. Endocrine Rev 3: 164-217.

14 Claus-Walker J, Scurry M, Carter RE, Campos RJ (1976) Steady state hormonal secretion in traumatic quadriplegia. J Clin Endocrinol Metab 44: 530-535.

15 Madsen M, Loven L, Smed S, Tegler L and Lennquist S (1986) 'The Low T3 Syndrome' and impaired thyroid protein synthesis in experimental trauma. Acta Chir Scand 152: 91-96.

16 Aun F, Medeiros-Neta GA, Younes RN, Birolini D, Ramos de Oliveira M (1983) The effect of major trauma on the pathways of thyroid hormone metabolism. J Trauma 23: 1048-1051.

17 Phillips RH, Valent WA, Caplan ES, Connor TB and Wiswell JG (1984) Circulating thyroid hormone changes in acute trauma: prognostic implications for clinical outcome. J Trauma 24: 1116-1119.

18 Vernikos-Danellis J, Leach CS, Winget CM, Rambaut PC and Mack PB (1972) Thyroid and adrenal corical rhythmicity during bed rest. J Appl Physiol 33: 644-648.

19 Burman KD, Smallridge RC, Osburne R, Dimond RC, Whorton NE, Kesler P, Wartofsky L (1980) Nature of suppressed TSH secretion during undernutrition: effect of fasting and refeeding on TSH responses to prolonged TRH infusions. Metabolism 29: 46-50.

20 Westren U, Ahren B, Burger A, Melander A (1977) Stimulation of peripheral T3 formation by oral but not by intravenous glucose administration in fasted subjects. Acta Endocrinol (Copen) 85: 526-529.

21 Gamstedt A, Jarerot G, Kagedal B and Soderholm B (1979) Corticosteroids and thyroid function. Acta Med Scand 205: 379-383.

22 Gamstedt A, Jarerot G, Kagedal B (1981) Dose related effects of betamethasone on iodothyronine and thyroid hormone binding proteins in serum. Acta Endocrinol 96: 484-490.

23 Grant JMF, Yeo JD (1968) Studies on levels of 17 hydoxy-corticoids in 24-hour specimens from five quadriplegic and two paraplegic patients admitted to the Royal Shore Hospital, Sidney. Paraplegia 6: $29-31$.

24 Tator CH 1983 Sunnybrook cord injury scales for assessing neurologic injury and neurologic recovery. In: Early Management of Acute Spinal Cord Injury, Chapter 2 p. 7-24, Raven Press, New York. 